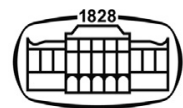

AKADÉMIAI KIADÓ

Resolution and

Discovery

$5(2020)$ 1, 5-12

DOI:

$10.1556 / 2051.2020 .00077$

(c) 2020 The Author(s)

ORIGINAL RESEARCH

PAPER

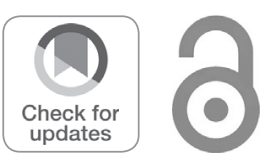

\section{Reduced graphene oxide-chitosan flexible nanocomposites for efficient bacteria capture and photothermal ablation}

\author{
MILICA BUDIMIR ${ }^{1,2,3 *} \odot$, DUŠKA KLEUT ${ }^{3}$, BILJANA \\ TODOROVIC MARKOVIC ${ }^{3}$ and RABAH BOUKHERROUB ${ }^{2}$
}

\author{
${ }^{1}$ School of Electrical Engineering, University of Belgrade, Bulevar kralja Aleksandra 73, 11000, \\ Belgrade, Serbia \\ ${ }^{2}$ Univ. Lille, CNRS, Centrale Lille, ISEN, Univ. Valenciennes, UMR 8520-IEMN, F-59000, Lille, France \\ 3 "Vinca" Institute of Nuclear Sciences - National Institute of the Republic of Serbia, University of \\ Belgrade, P. O. Box 522, 11000, Belgrade, Serbia
}

Received: July 15, 2019 • Accepted: March 11, 2020

Published online: August 14, 2020

\begin{abstract}
One of the major public health concerns today is bacterial infection-associated diseases. Traditional antibacterial therapies are becoming less efficient because frequent and inadequate use of antibiotics has caused mutations in bacteria that led to many antibiotic-resistant bacterial strains. It is, therefore, crucial to develop novel antibacterial materials and strategies that will successfully combat both grampositive and gram-negative bacteria. In the present study, we will demonstrate a simple and efficient method for bacteria capture and elimination through photothermal ablation. The developed material consists of a flexible Kapton substrate, coated with reduced graphene oxide-chitosan (rGO-CS) thin films. Reduced graphene oxide has strong absorption in the near-infrared (NIR) region, while chitosan has the ability to bind bacteria through electrostatic interactions. The $\mathrm{K} / \mathrm{rGO}$-CS device proved to capture and efficiently eradicate both planktonic Gram-positive Staphylococcus aureus (S. aureus) and Gram-negative Escherichia coli (E. coli) bacteria after $10 \mathrm{~min}$ of NIR $(980 \mathrm{~nm})$ irradiation.
\end{abstract}

\section{KEYWORDS}

reduced graphene oxide, chitosan, photothermal, bacteria eradication

\section{INTRODUCTION}

Today, there is an urgent need for alternatives to antibiotics, and new antibacterial materials or coatings that would prevent bacterial colonization [1]. Bacterial infections are a serious threat to human health, water quality, food storage, etc. Decades of the misuse of antibiotics in human and animal therapies, but also in agriculture, has led to the rise of antibiotic-resistant bacterial strains [2]. There is an estimation that today, around 829,000 people die annually from diseases caused by unsafe drinking water [3], mostly in developing countries. Nevertheless, in U.S. acute care hospitals in 2015, about 72,000 patients with hospital-acquired infections died during their hospitalizations [4]. These alarming numbers highlight the importance of finding new antimicrobial agents and surfaces to fight both Gram-positive and Gram-negative bacteria and their biofilms.

Nanomaterials and nanotechnology offer a potential replacement for conventional treatment techniques and the design of antibacterial surfaces [5]. Nanomaterials (usually ranging from 1 to $100 \mathrm{~nm}$ ) exhibit unique physical, chemical and biological properties which are quite different compared to their macro scaled counterparts. Today, nanotechnology-based materials provide a solution to many technological and environmental challenges in different fields, such as water technology, solar energy, catalysis, and medicine [6]. Nanomaterials could be used in forms of nanoparticles (NPs) or nanocomposites, and mechanisms of their interaction with 
bacteria are numerous [7]. Their main advantage over traditional antibiotics is the fact that NPs fight the microbes via multiple mechanisms simultaneously [8]. For this reason, microbes are unlikely to develop resistance against them, because it is not likely to have multiple mutated genes.

Graphene is a 2D material consisted of carbon atoms that are tightly bound in a hexagonal honeycomb lattice, which has been extensively studied over the last decade due to its remarkable physical, chemical, optical, electronic and thermal properties $[9,10]$. However, recently, it has attracted the attention of many researchers for biological applications, including biosensors, tissue engineering, and the design of antibacterial materials [11-14]. In order to improve the antibacterial activity of graphene, some research groups have prepared its nanocomposites with different polymers such as chitosan [15, 16], polyamide [17], polyethyleneimine (PEI) [18] or poly(vinyl alcohol) [19]. Chitosan is a cationic biopolymer derived from chitin, with promising antimicrobial properties, excellent biocompatibility and biodegradability [20]. Due to its positive charge, chitosan can easily interact with negatively charged bacteria. However, the low mechanical strength limits some of its applications [16].

Photothermal antibacterial therapy includes the usage of photothermal agents, that are capable of fast conversion of near-infrared (NIR) light into heat. NIR light is advantageous due to its deep penetration into tissues, without harming the surrounding cells. High temperatures cause damage to the cell membrane of bacteria subsequently leading to their death. Graphene and graphene-based materials have been extensively studied for PTT, due to their strong absorption in the NIR region. Recently Luo et al. prepared nanocellulose paper decorated with graphene oxide and gold nanoparticles for NIR $(808 \mathrm{~nm})$ triggered photothermal ablation of bacteria [21]. Colleagues from our group have recently investigated the synergistic effect of gold nanorods and rGO on Escherichia coli strain and demonstrated the killing efficiency of $99 \%$ of bacteria in the solution after only $10 \mathrm{~min}$ [22]. They could also achieve a targeted killing of E. coli UTI89 by functionalizing graphene coating with multimeric heptyl $\alpha$-D-mannoside probes. A group of researchers recently designed a nanocomposite consisted of $\mathrm{Ag} / \mathrm{ZnO} / \mathrm{rGO}$, with a synergistic antibacterial effect. This nanocomposite combined photocatalytic properties of $\mathrm{ZnO}$ nanoparticles, high specific surface area and NIR photothermal conversion property of rGO and multiple mechanisms of bacteria-killing of Ag. Also, this nanocomposite took advantage of surface-enhanced Raman scattering (SERS) property of Ag, so apart from antibacterial, it had the potential for SERS detection of bacteria [23].

In the present work, we will demonstrate the antibacterial composite consisted of reduced graphene oxidechitosan (rGO-CS) coated flexible Kapton interface. To design this simple photothermal nanocomposite we took advantage of excellent photothermal properties of rGO and cationic nature of chitosan. This technique is simple and has the potential for the elimination of different micro-organisms.

\section{EXPERIMENTAL}

\section{Chemicals}

Chitosan (CS) of low molecular weight (50,000-190,000) was purchased from Sigma Aldrich (Darm-stadt, Germany), and reduced graphene oxide ( $\mathrm{rGO}$ ) was purchased from Graphenea. Kapton HN polyimide foils with a thickness of $125 \mu \mathrm{m}$ were obtained from DuPont (Circleville, OH, USA).

\section{Preparation of Kapton coated with reduced graphene oxide-chitosan (K/rGO-CS)}

A dispersion of chitosan was prepared in $1 \%$ acetic acid (1 $\mathrm{mg} / \mathrm{mL}$ ). Reduced graphene oxide was dispersed in Mili-Q water $(1 \mathrm{mg} / \mathrm{mL})$, sonicated for $5 \mathrm{~h}$ and stirred overnight. The dispersion of rGO was then slowly added to the dispersion of CS in the weight ratio 2:1, and stirred overnight.

Kapton foils were cut into small pieces $\left(10 \times 10 \mathrm{~mm}^{2}\right)$ and cleaned in ethanol in an ultrasonic water bath for 20 $\mathrm{min}$. Then, they were modified with $\mathrm{rGO}-\mathrm{CS}(1 \mathrm{mg} / \mathrm{mL})$ by drop-casting $(100 \mu \mathrm{L})$ two times, each time followed by drying at room temperature. As a control sample, we also drop-casted a dispersion of $\mathrm{rGO}$ in water $(1 \mathrm{mg} / \mathrm{mL})$ on Kapton surfaces, however, these samples were not stable, and rGO was detaching from the Kapton surface.

\section{Measurement of the photothermal effect}

For photothermal experiments, a continuous wave laser (Gbox model, Fournier Medical Solution) of a power density $2 \mathrm{~W} \mathrm{~cm}^{-2}$ with an output light at $980 \mathrm{~nm}$, was used. This laser was injected into a $400 \mu \mathrm{m}$-core fiber and placed around $3 \mathrm{~cm}$ away from the bottom of the wells. The temperature changes were captured by an Infrared Camera (Thermovision A40) and treated using ThermaCam Researcher Pro 2.9 software.

\section{Bacteria culture preparation}

For the antibacterial assays, a Gram-negative Escherichia coli (E. coli) and a Gram-positive Staphylococcus aureus (S. aureus) were used. A single E. coli K12 or S. aureus colony from Mueller Hinton $(\mathrm{MH})$ agar plate was inoculated overnight in $\mathrm{MH}$ medium at $37{ }^{\circ} \mathrm{C}$ with mild shaking. The pre-culture was diluted 50-fold and allowed to continue growth for another 3-4 h, until the optical density at $600 \mathrm{~nm}$ $\left(\mathrm{OD}_{600}\right)$ had reached $0.6-1$. The bacterial cells were re-suspended in phosphate-buffered saline solution (PBS) and adjusted to the required concentration.

\section{Antibacterial activity experiments}

To assess the ability of K/rGO-CS matrix to capture and kill bacteria, each substrate was immersed in $1 \mathrm{~mL}$ of a bacterial suspension at a concentration of $10^{8} \mathrm{cfu} \mathrm{mL}^{-1}$ for $2 \mathrm{~h}$ at $37^{\circ} \mathrm{C}$ with shaking $(150 \mathrm{rpm})$, and then we performed a few different experiments. Firstly, after incubation, $200 \mu \mathrm{L}$ of 
$10^{3}$-fold diluted planktonic bacteria were spread onto $\mathrm{MH}$ agar plates and the plates were incubated at $37^{\circ} \mathrm{C}$ overnight. This test was performed in order to evaluate the viability of bacteria exposed to the $\mathrm{K} / \mathrm{rGO}-\mathrm{CS}$ interface without laser irradiation. Then, the samples were gently rinsed with Mili$\mathrm{Q}$ water to remove the non-adherent cells and transferred to a new 12-well plate, where $1 \mathrm{~mL}$ of water was added to each well. Samples were then exposed to NIR laser at $980 \mathrm{~nm}$, for $10 \mathrm{~min}$ at $2 \mathrm{~W} \mathrm{~cm}^{-2}$ laser power density. The other interfaces were kept as a control, without laser irradiation. We performed an experiment of direct application of $\mathrm{K} / \mathrm{rGO}-\mathrm{CS}$ interfaces to fresh $\mathrm{MH}$ agar plates for both, irradiated and non-irradiated interface. Also, we used an aliquot of $500 \mu \mathrm{L}$ solution from each well, to spread it onto separate $\mathrm{MH}$ agar plates. All the agar plates were incubated at $37{ }^{\circ} \mathrm{C}$ overnight, and after the bacterial growth was evaluated. We performed the same experiments on both E. coli and S. aureus strains, and all the experiments were performed in triplicates.

\section{Characterization}

UV-vis spectroscopic measurements were carried out using a UV-vis SAFAS spectrophotometer in the wavelength range between 200 and $1,000 \mathrm{~nm}$ with $1 \mathrm{~nm}$ step. The concentration of water dispersions of samples $(0.25 \mathrm{mg} / \mathrm{mL})$ was recorded at room temperature.

Contact angle measurements were performed by a remotecomputer controlled goniometer system (DIGIDROP by GBX). The contact angle was measured using $2 \mu \mathrm{L}$ of deionized water. The accuracy is $\pm 2^{\circ}$, and all measurements were performed in the ambient atmosphere at room temperature.
Zeta potential measurements were performed in Zetasizer Malverin. Water dispersions of samples were $(10 \mu \mathrm{g} / \mathrm{mL})$ recorded in the ambient atmosphere at room temperature.

Atomic Force Microscopy (AFM) measurements were performed using Quesant (Agoura Hills, CA) microscope operating in tapping mode in the air, at room temperature. Water dispersions $(0.5 \mathrm{mg} / \mathrm{mL})$ of samples were spin-coated on a mica substrate.

\section{RESULTS AND DISCUSSION}

Suspension of rGO-CS was chemically stable in water for a longer period of time. As illustrated in Fig. 1, the addition of rGO in chitosan solution led to the formation of the "cloud" of chitosan around rGO sheets, conferring the whole solution a positive charge which was further confirmed by Zeta potential measurements and AFM images. Chitosan molecules were wrapping rGO sheets through electrostatic interactions and endowed a positive charge and good dispersibility in water to rGO.

Fang et al. [24] explored the GO-CS suspensions, and their results revealed that the Zeta potential was different depending on the order of adding and mixing suspensions. When GO was gradually added to chitosan solution (with stirring), the zeta potential was $+40 \mathrm{mV}$, while, when chitosan was added to GO suspension, the zeta potential was still positive, but much lower $(+8 \mathrm{mV})$ [24].

In our experiment, the results of Zeta potential measurements showed that Reduced graphene oxide bears a negative charge $Z=-32 \mathrm{mV}$. However, after the reaction

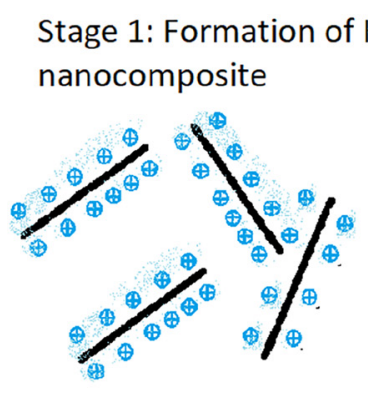

rGO-CS in water

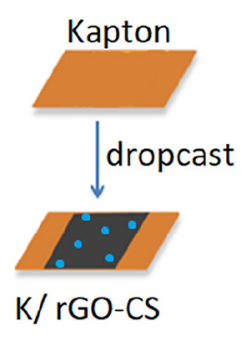

$\mathrm{K} / \mathrm{rGO}-\mathrm{CS}$

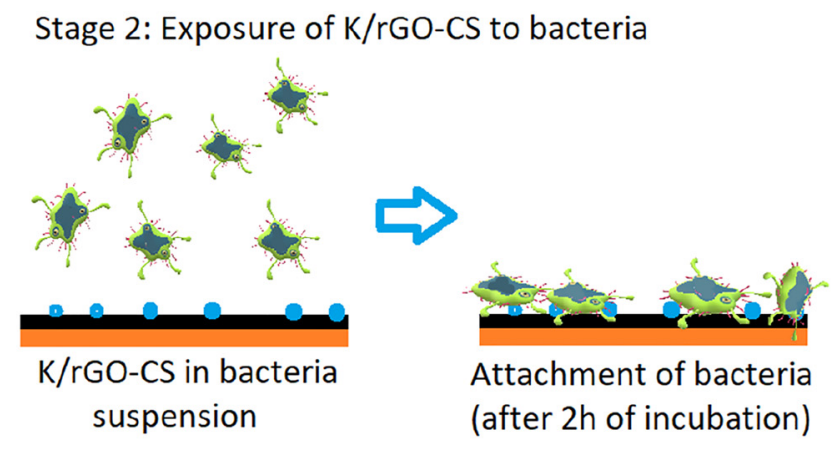

Stage 3: Laser irradiation
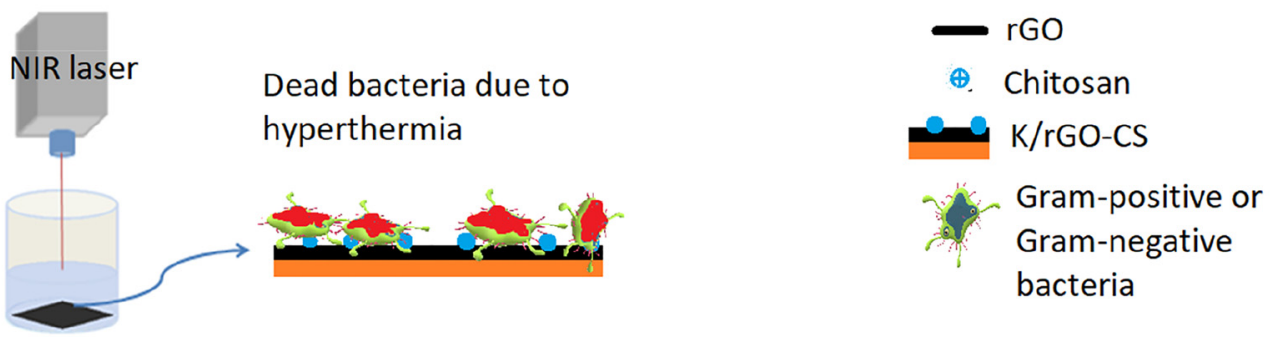

Fig. 1. A sketch illustrating the formation of reduced graphene oxide-chitosan coated nanocomposites (K/rGO-CS) and their application in bacteria capture and photothermal killing 
with chitosan, Zeta potential measurements confirmed the positive charge of rGO-CS solution, with the mean value $Z=+46 \mathrm{mV}$ (Fig. 2). This property is advantageous because cell membranes of the bacteria are negatively charged, therefore they can easily interact with $\mathrm{K} / \mathrm{rGO}-\mathrm{CS}$ surface through electrostatic interactions.

The absorption spectra of the prepared rGO-CS and starting materials were analyzed through UV-vis spectrophotometry in the 200-1,000 $\mathrm{nm}$ range (Fig. 3a). CS absorbs below $230 \mathrm{~nm}$ as expected for a biopolymer. As can be seen from the spectra, the absorption of the rGO-CS sample in the NIR region $(700-1,000 \mathrm{~nm})$ did not change compared to rGO alone, therefore the presence of CS does not influence the photothermal properties of rGO.

The photothermal properties were assessed through irradiation with a $980 \mathrm{~nm}$-continuous wave laser, while the samples were placed in wells with $1 \mathrm{~mL}$ of MQ water for 10 min; the diameter of the laser beam was adjusted directly to the well. The photothermal properties of Kapton foil were evaluated for comparison, and it reached $30{ }^{\circ} \mathrm{C}$. Upon coating with rGO-CS, the temperature increased up to $65^{\circ} \mathrm{C}$ using the same photothermal irradiation conditions, indicating its enhanced photothermal heating ability (Fig. 3b).

The wetting properties of the prepared interfaces were examined by water contact angle (WCA) measurements. The surface of Kapton exhibits a hydrophobic character with a WCA of $105^{\circ}$. However, after coating Kapton with rGO-CS, the contact angle decreases to $53^{\circ}$, conferring a hydrophilic character to the surface (Fig. 4a and b). This property is beneficial because it can improve the contact between bacteria and the sample.

AFM was performed to visualize the $\mathrm{rGO}$ and $\mathrm{rGO}-\mathrm{CS}$ morphology. As can be observed from (Fig. 5a and b) there are layers of chitosan anchored on the surface of rGO sheets. These images confirmed that chitosan was successfully grafted to rGO surface, and significantly increased the thickness of $\mathrm{rGO}$, which is presented by the height profile images (Fig. $5 \mathrm{c}$ and d). In Table 1 we can compare the average height of $\mathrm{rGO}$ and $\mathrm{rGO}-\mathrm{CS}$ calculated from multiple AFM image profiles. Also, from AFM images, we could notice that there was a very small quantity of unbonded CS in the solution of rGO-CS.

\section{Antibacterial activity of $\mathrm{K} / \mathrm{rGO}-\mathrm{CS}$ interface}

Bacteria viability test for the cells after $2 \mathrm{~h}$ of incubation on $\mathrm{K} / \mathrm{rGO}-\mathrm{CS}$ interfaces, without laser irradiation, showed that the amount of viable $E$. coli and $S$. aureus was almost the same to the control group, proving that the $\mathrm{rGO}-\mathrm{CS}$ coating itself was not toxic to bacteria at such high concentrations, without laser irradiation (Fig. 6). This is in accordance with our previously obtained results for the coating of rGO and polyethyleneimine [18]. Also, previous studies of our colleagues from the group showed that the exfoliated graphene and GO did not have antibacterial properties [25, 26], and they did not produce singlet
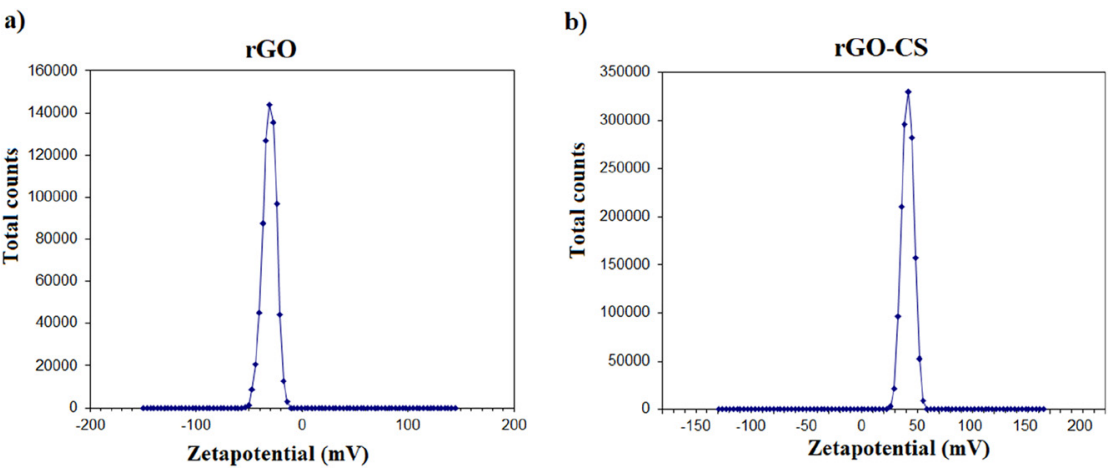

Fig. 2. Zeta potential measurements of (a) rGO and (b) rGO-CS
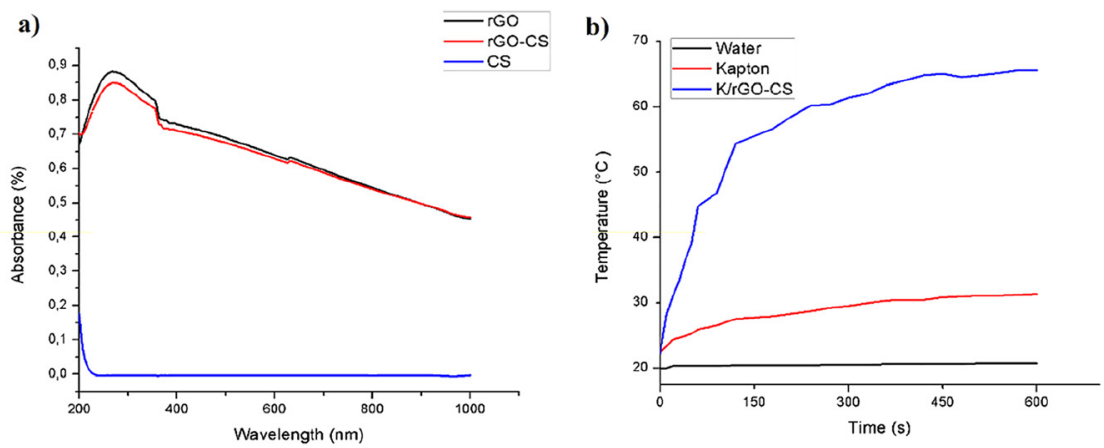

Fig. 3. (a) UV-vis absorbance spectra of rGO, rGO-CS, and CS; (b) Temperature changes of different samples after 10 min of NIR irradiation at $2 \mathrm{~W} \mathrm{~cm}^{-2}$ 

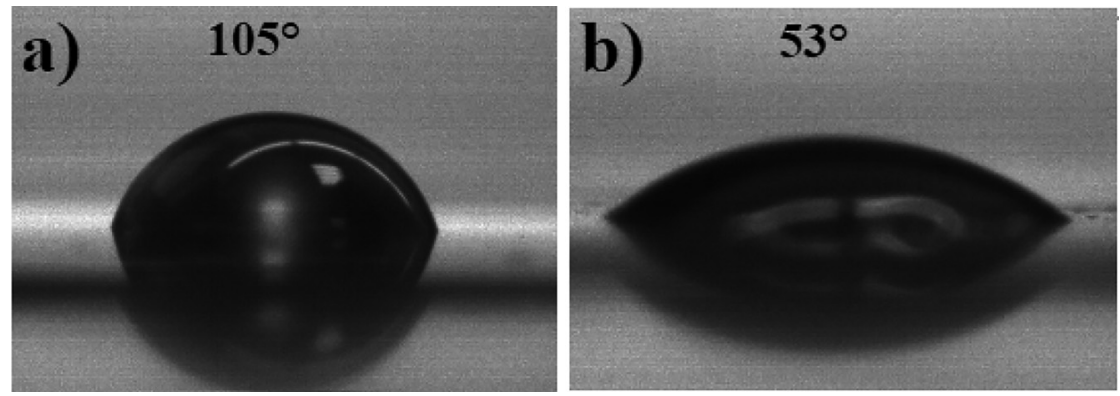

Fig. 4. Water contact angle measurements of (a) Kapton and (b) K/rGO-CS
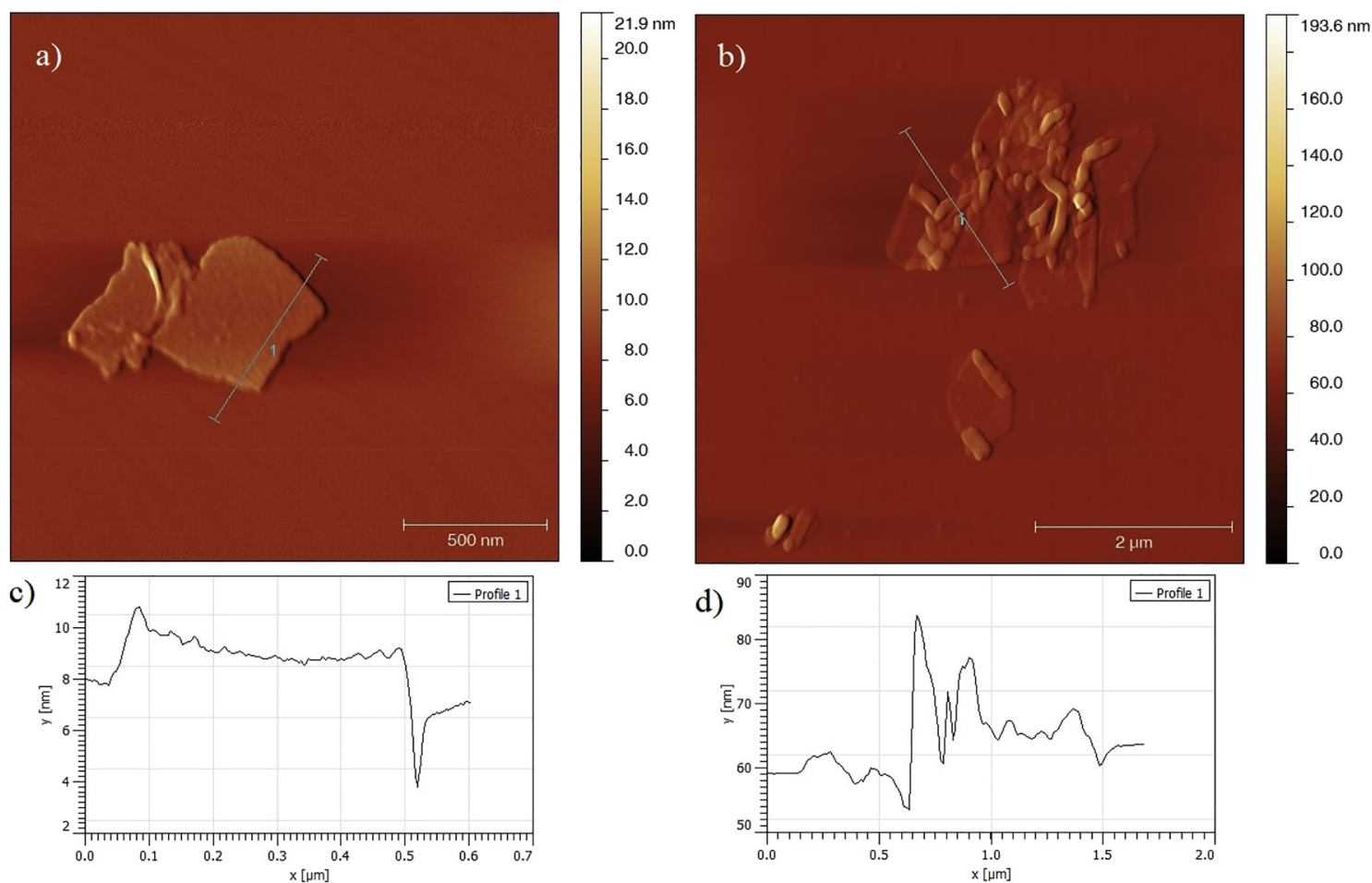

Fig. 5. AFM images and profiles of rGO ( $\mathrm{a}$ and c), and rGO-CS ( $\mathrm{b}$ and d). The scanned surfaces are $2 \times 2$ and $5 \times 5 \mu \mathrm{m}^{2}$, respectively.

oxygen, which is usually responsible for antibacterial activity of GO [27].

Another viability test was performed for the cells detached in an aqueous medium after laser irradiation. From Fig. 7 , we can notice that the supernatant was sterile after irradiation (Fig. 7a). However, for a control, K/rGO-CS without laser irradiation, the supernatant containing detached cells, grew on the agar plate.

From the performed experiments, we can conclude that the significant increase of temperature on the surface of $\mathrm{K} /$ rGO-CS interface has caused the disruptions of cell membranes on the bacterial cells attached to the $\mathrm{K} / \mathrm{rGO}$ CS interface, and consequently the bacterial cell death. The killing mechanism was hyperthermia, and the efficiency was calculated from the visual images of bacterial colonies grown on $\mathrm{MH}$ agar plates, formed after direct application of Kapton/rGO-CS surfaces on agar and incubation at $37{ }^{\circ} \mathrm{C}$ for 20 h. In Fig. $7 \mathrm{c}$ it is presented how the bacterial colonies densely grew in the spot where the control $\mathrm{K} / \mathrm{rGO}-\mathrm{CS}$ interface touched the agar plate, and almost no bacteria in the place where NIR laser exposed $\mathrm{K} / \mathrm{rGO}-\mathrm{CS}$ interface was in direct contact with the agar plate. Statistical analyses were performed by Image open-source

Table 1. The dimensions of rGO and rGO-CS

\begin{tabular}{lc}
\hline Sample & Height \\
\hline rGO & $1.2 \mathrm{~nm}$ \\
rGO-CS & $8 \mathrm{~nm}$ \\
\hline
\end{tabular}



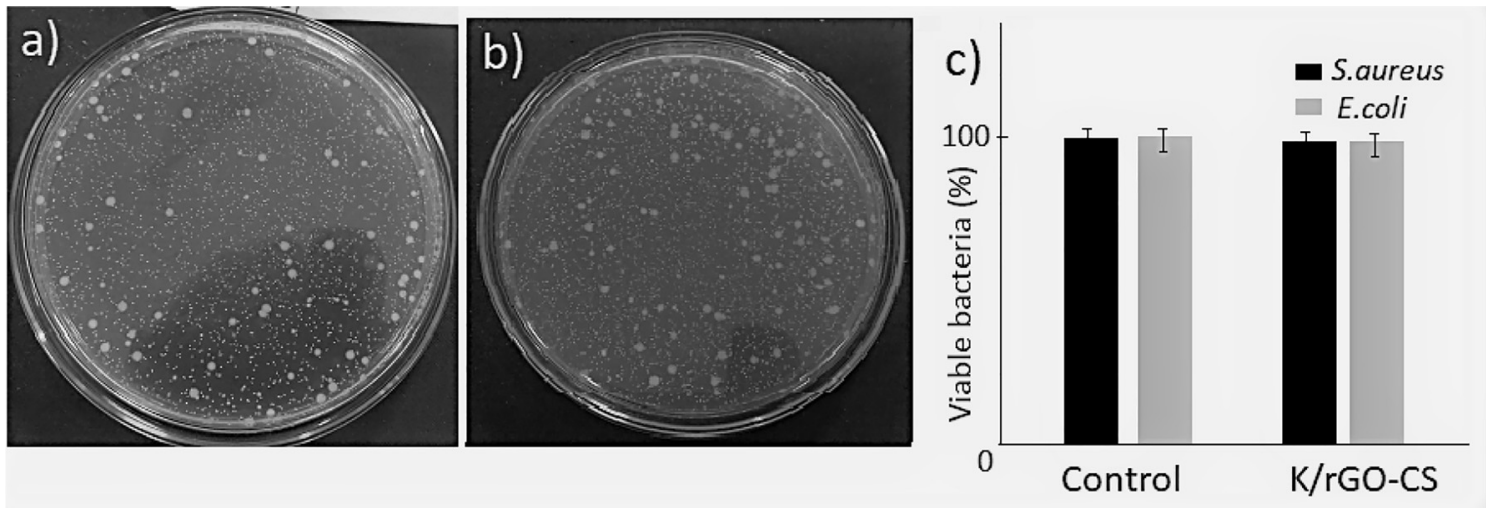

Fig. 6. Typical photographs of S. aureus colonies grown for the (a) control and (b) after $2 \mathrm{~h}$ of incubation with K/rGO-CS; (c) corresponding statistical histograms for both strains
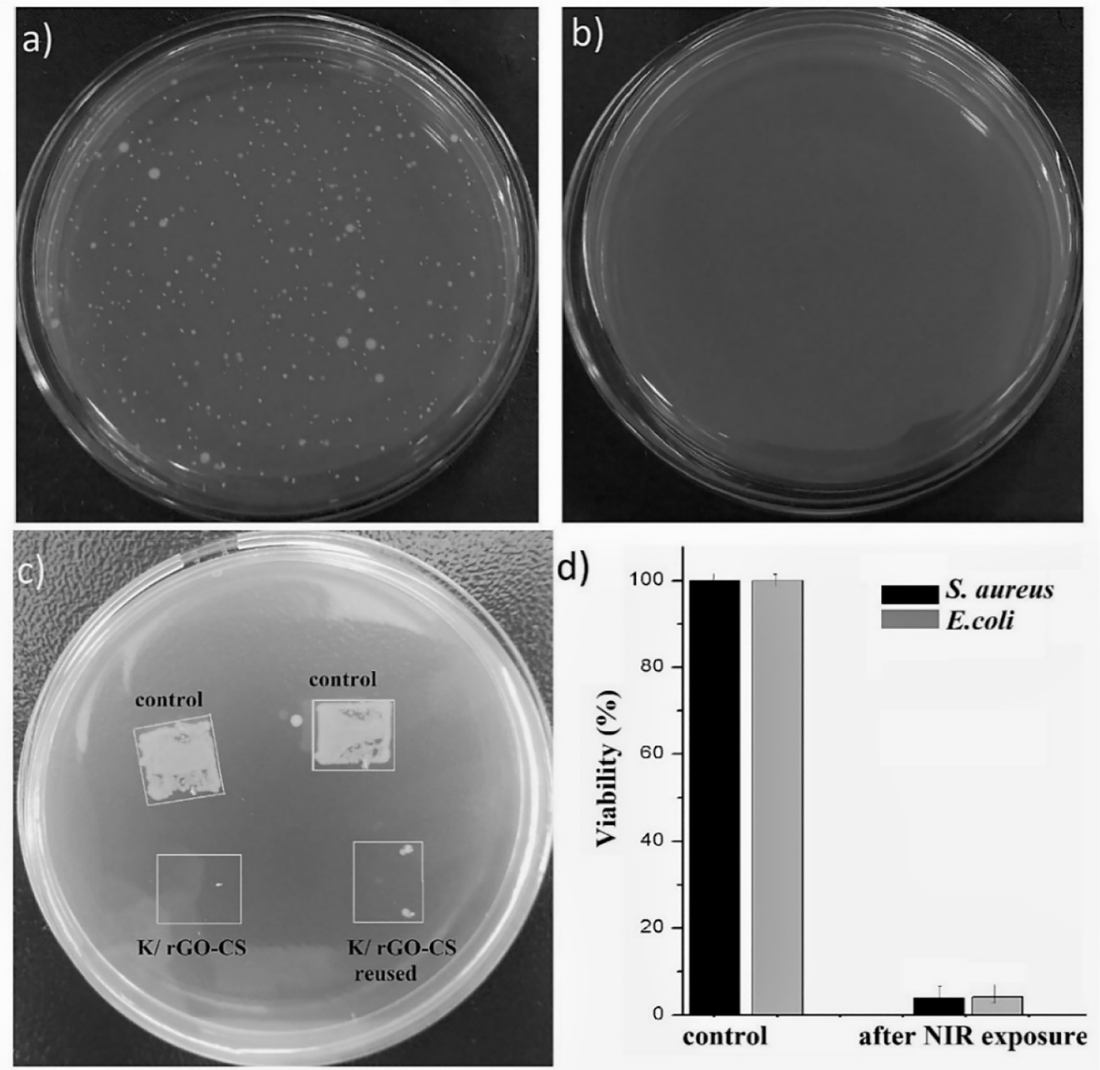

Fig. 7. (a) Plate showing the S. aureus bacteria detached from K/rGO-CS into surrounding water without laser irradiation; (b) the bacteria detached during the NIR laser irradiation did not grow; (c) Contact plate assay for E. coli bacteria showing the two control samples without NIR irradiation, and K/rGO-CS (new and reused sample) sample after NIR laser irradiation; (d) Bacteria viability evaluation before and after NIR laser exposure for E. coli and S. aureus bacteria

treatment program. As indicated by analysis, the viability rate of the bacteria from the surface had similar values for both strains (5\% for S. aureus and 6\% for E. coli).

\section{Reuse of K/rGO-CS}

The ideal antibacterial nanocomposite should be able to be used again in order to reduce the cost of production.
After the capture and heating experiments the K/rGO-CS sample was rinsed in water and ethanol and after drying the antibacterial experiments were repeated. The heating ability of $\mathrm{K} / \mathrm{rGO}-\mathrm{CS}$ nanocomposite remained unchanged. The antibacterial efficiency was only slightly reduced, which was confirmed by the direct application of reused $\mathrm{K} / \mathrm{rGO}-\mathrm{CS}$ surfaces on agar plates (Fig. 6c). 


\section{CONCLUSION}

In this work, we presented Kapton/rGO-CS nanocomposite, which is a simple and straightforward method of bacteria capture and eradication through NIR irradiation. We demonstrated that the Kapton/rGO-CS was efficient in bacteria capture, due to the presence of CS which brings a positive charge to the surface. Additionally, the captured bacteria were efficiently killed by hyperthermia, caused by the low power NIR $(980 \mathrm{~nm})$ laser irradiation, and excellent photothermal properties of rGO. Our results demonstrate that Kapton/rGO-CS nanocomposite is universal, and has a great potential for different antibacterial applications.

\section{ACKNOWLEDGMENTS}

This research is funded by the Centre National de la Recherche Scientifique (CNRS), the University Lille, the Hauts-de-France region, the CPER "Photonics for Society", the Agence Nationale de la Recherche (ANR) and the EU union through FLAG-ERA JTC 2015-Graphtivity. Additionally, it is supported by the Ministry of Education, Science and Technological Development of the Republic of Serbia through national project No. 17003 and Grant No. 451-03-68/202014/200017.

\section{REFERENCES}

1. Stewart, P. S.; Costerton, J. W. Antibiotic resistance of bacteria in biofilms. Lancet 2001, 358, 135-8. https://doi.org/10.1016/S01406736(01)05321-1.

2. Pelgrift, R. Y.; Friedman, A. J. Nanotechnology as a therapeutic tool to combat microbial resistance. Adv. Drug. Deliv. Rev. 2013, 65, 1803-15. https://doi.org/10.1016/J.ADDR.2013.07.011.

3. World Health Organization. Guidelines for Drinking-Water Quality, 4th ed.; Incorporating the First Addendum, 2014.

4. Magill, S. S.; O'Leary, E.; Janelle, S. J.; Thompson, D. L.; Dumyati, G.; Nadle, J.; Wilson, L. E.; Kainer, M. A.; Lynfield, R.; Greissman, S.; Ray, S. M. Changes in prevalence of health care-associated infections in U.S. Hospitals. N. Engl. J. Med. 2018, 379, 1732-44. https://doi.org/10.1056/NEJMoa1801550.

5. Hasan, J.; Crawford, R. J.; Ivanova, E. P. Antibacterial surfaces: The quest for a new generation of biomaterials. Trends. Biotechnol. 2013, 31, 295-304. https://doi.org/10.1016/j.tibtech.2013.01.017.

6. Armentano, I.; Arciola, C. R.; Fortunati, E.; Ferrari, D.; Mattioli, S.; Amoroso, C. F.; Rizzo, J.; Kenny, J. M.; Imbriani, M.; Visai, L. The interaction of bacteria with engineered nanostructured polymeric materials: a review, The Scientific World Journal 2014, 14. https:// doi.org/10.1155/2014/410423.

7. Hajipour, M. J.; Fromm, K. M.; Akbar Ashkarran, A.; Jimenez de Aberasturi, D.; de Larramendi, I. R.; Rojo, T.; Serpooshan, V.; Parak, W. J.; Mahmoudi, M. Antibacterial properties of nanoparticles. Trends Biotechnol. 2012, 30, 499-511. https://doi.org/10. 1016/J.TIBTECH.2012.06.004.
8. Wang, L.; Hu, C.; Shao, L. The antimicrobial activity of nanoparticles: Present situation and prospects for the future. Int. J. Nanomedicine 2017, 12, 1227-49. https://doi.org/10.2147/IJN.S121956.

9. Novoselov, K. S.; Jiang, D.; Schedin, F.; Booth, T. J.; Khotkevich, V. V.; Morozov, S. V.; Geim, A. K. Two-dimensional atomic crystals. Proc. Natl. Acad. Sci. U S A 2005, 102, 10451-3. https://doi.org/10. 1073/pnas.0502848102.

10. Avouris, P.; Dimitrakopoulos, C. Graphene: Synthesis and applications. Mater. Today 2012, 15, 86-97. https://doi.org/10.1016/ S1369-7021(12)70044-5.

11. Szunerits, S.; Boukherroub, R. Antibacterial activity of graphenebased materials. J. Mater. Chem. B 2016, 4, 6892-912. https://doi. org/10.1039/c6tb01647b.

12. Sanchez, V. C.; Jachak, A.; Hurt, R. H.; Kane, A. B. Biological interactions of graphene-family nanomaterials: An interdisciplinary review. Chem. Res. Toxicol. 2012, 25, 15-34. https://doi.org/10. 1021/tx200339h.

13. Pumera M. Graphene in biosensing. Mater. Today 2011, 14, 308-15. https://doi.org/10.1016/S1369-7021(11)70160-2.

14. Shin, S. R.; Li, Y. C.; Jang, H. L.; Khoshakhlagh, P.; Akbari, M.; Nasajpour, A.; Zhang, Y. S.; Tamayol, A.; Khademhosseini, A. Graphene-based materials for tissue engineering. Adv. Drug. Deliv. Rev. 2016, 105, 255-74. https://doi.org/10.1016/j.addr.2016.03.007.

15. Jia, X.; Ahmad, I.; Yang, R.; Wang, C. Versatile graphene-based photothermal nanocomposites for effectively capturing and killing bacteria, and for destroying bacterial biofilms. J. Mater. Chem. B 2017, 5, 2459-67. https://doi.org/10.1039/C6TB03084J.

16. Lim, H. N.; Huang, N. M.; Loo, C. H. Facile preparation of graphene-based chitosan films: Enhanced thermal, mechanical and antibacterial properties. J. Non. Cryst. Solids 2012, 358, 525-30. https://doi.org/10.1016/J.JNONCRYSOL.2011.11.007.

17. Perreault, F.; Tousley, M. E.; Elimelech, M. Thin-film composite polyamide membranes functionalized with biocidal graphene oxide nanosheets. Environ. Sci. Technol. Lett. 2014, 1, 71-6. https://doi. org/10.1021/ez4001356.

18. Budimir, M.; Jijie, R.; Ye, R.; Barras, A.; Melinte, S.; Silhanek, A.; Markovic, Z.; Szunerits, S.; Boukherroub, R. Efficient capture and photothermal ablation of planktonic bacteria and biofilms using reduced graphene oxide-polyethyleneimine flexible nanoheaters. J. Mater. Chem. B 2019, 7, 2771-81. https://doi.org/10.1039/c8tb01676c.

19. Liu, Y.; Park, M.; Shin, H. K.; Pant, B.; Choi, J.; Park, Y. W.; Lee, J. Y.; Park, S. J.; Kim, H. Y. Facile preparation and characterization of poly(vinyl alcohol)/chitosan/graphene oxide biocomposite nanofibers. J. Ind. Eng. Chem. 2014, 20, 4415-20. https://doi.org/10. 1016/J.JIEC.2014.02.009.

20. Kong, M.; Chen, X. G.; Xing, K.; Park, H. J. Antimicrobial properties of chitosan and mode of action: A state of the art review. Int. J. Food. Microbiol. 2010, 144, 51-63. https://doi.org/10.1016/J. IJFOODMICRO.2010.09.012.

21. Luo, J.; Deng, W.; Yang, F.; Wu, Z.; Huang, M.; Gu, M. Gold nanoparticles decorated graphene oxide/nanocellulose paper for NIR laser-induced photothermal ablation of pathogenic bacteria. Carbohydr. Polym. 2018, 198, 206-14. https://doi.org/10.1016/j. carbpol.2018.06.074.

22. Turcheniuk, K.; Hage, C.-H. H.; Spadavecchia, J.; Serrano, A. Y.; Larroulet, I.; Pesquera, A.; Zurutuza, A.; Pisfil, M. G.; Héliot, L.; Boukaert, J.; Boukherroub, R. Plasmonic photothermal destruction of uropathogenic E. coli with reduced graphene oxide and core/shell 
nanocomposites of gold nanorods/reduced graphene oxide. J. Mater. Chem. B 2015, 3, 375-86. https://doi.org/10.1039/C4TB01760A.

23. Ko, Y. C.; Fang, H. Y.; Chen, D. H. Fabrication of Ag/ZnO/reduced graphene oxide nanocomposite for SERS detection and multiway killing of bacteria. J. Alloys. Compd. 2017, 695, 1145-53. https://doi. org/10.1016/j.jallcom.2016.10.241.

24. Fang, M.; Long, J.; Zhao, W.; Wang, L.; Chen, G. pH-responsive chitosan-mediated graphene dispersions. Langmuir 2010, 26, 16771-4. https://doi.org/10.1021/la102703b.

25. Marković, Z. M.; Jovanović, S. P.; Mašković, P. Z.; Danko, M.; Mičušík, M.; Pavlović, V. B.; Milivojević, D. D.; Kleinová, A.; Špitalský, Z.; Marković, B. M. Photo-induced antibacterial activity of four graphene based nanomaterials on a wide range of bacteria. RSC Adv. 2018, 8, 31337-47. https://doi.org/10.1039/C8RA04664F.
26. Marković, Z. M.; Matijašević, D. M.; Pavlović, V. B.; Jovanović, S. P.; Holclajtner-Antunović, I. D.; Špitalský, Z.; Mičušik, M.; Dramićanin, M. D.; Milivojević, D. D.; Nikšić, M. P.; Marković, B. M. Antibacterial potential of electrochemically exfoliated graphene sheets. J. Colloid. Interface. Sci. 2017, 500, 30-43. https://doi.org/10.1016/j.jcis.2017.03.110.

27. Marković, Z. M.; Jovanović, S. P.; Mašković, P. Z.; Mojsin, M. M.; Stevanović, M. J.; Danko, M.; Mičušík, M.; Jovanović, D. J.; Kleinová, A.; Špitalský, Z.; Pavlović, V. B. Graphene oxide size and structure pro-oxidant and antioxidant activity and photoinduced cytotoxicity relation on three cancer cell lines. J. Photochem. Photobiol. B Biol. 2019, 200. https://doi.org/10.1016/j. jphotobiol.2019.111647. 